\title{
Implantação de biomembrana de colágeno tratada em solução alcalina ou conservada em glicerina a $98 \%$ na parede abdominal de equinos
}

\author{
Implantation of collagen biomembrane treated in alkaline solution or conserved in $98 \%$ \\ glycerin in the abdominal wall of horses
Valcinir Aloisio Scalla Vulcani ${ }^{\text {I* }}$ Delphim da Graça Macoris ${ }^{\text {II }}$ Ana Maria de Guzzi Plepis ${ }^{\text {III }}$ Virgínia da Conceição Amaro Martins ${ }^{\text {III }}$ Vanessa Sobue Franzo $^{\text {IV }}$ Rogério Elias Rabelo $^{\text {I }}$ Fabiano José Ferreira de Sant'Ana ${ }^{I}$

\section{RESUMO}

Objetivou-se, neste trabalho, obter biomembranas de colágeno tratadas em solução alcalina por 72 horas (GE), a partir de centros tendinosos diafragmáticos de equinos e comparar sua biocompatibilidade com membranas conservadas em solução de glicerina a $98 \%(G G)$ e membranas não tratadas $(G C)$. As membranas foram implantadas na fáscia interna do músculo reto do abdome de equinos e retiradas, juntamente com os tecidos adjacentes, aos sete, 63 e 126 dias pós-operatórios para a preparação de lâminas histológicas. O estudo histomorfométrico das laminas revelou processo inflamatório mais intenso para os implantes GG e CC e cicatrização mais rápida para os implantes GE. Concluiu-se que as biomembranas colagênicas tratadas em solução alcalina são mais biocompatíveis do que biomembranas conservadas em glicerina $98 \%$.

Palavras-chave: biomateriais, implante, cicatrização, cirurgia reparadora.

\section{ABSTRACT}

The objective of this research was obtain collagen biomembranes treated in alkaline solution for 72 hours $(G E)$ from tendineous diaphragmatic center of equines and compare its biocompatibility with membranes preserved in a glycerin solution $98 \%(G G)$ and membranes do not treated $(G C)$. The membranes were implanted in the internal fascia of recto abdominis muscle of equines and removed, with adjacent tissues, seven, 63 and 126 days postoperative for the preparation of histological slides. The histomorphometric study revealed more intense inflammatory process to $G G$ and $C C$ implants and faster healing for $G E$ implants. It was concluded that the collagen biomembranes treated in alkaline solution is more biocompatible than biomembranes preserved in $98 \%$ glycerin.

Key words: biomaterial, implant, healing, reconstructive surgery.

\section{INTRODUÇÃO}

Areparação cirúrgica ou reforço dos tecidos que compõem a parede abdominal é uma necessidade constante na cirurgia humana e veterinária. Diversos materiais têm sido empregados, como próteses na parede abdominal, no entanto, muitos deles têm induzido reações severas no hospedeiro, rejeições e infecções (BELLÓN, 1995; VULCANI et al., 2009).

Dentre os materiais naturais utilizados, tecidos animais colagênicos têm sido frequentemente aplicados no abdômen de animais, o que requer conservação para preservar sua viabilidade e diminuir sua antigenicidade. A preservação tem sido feita por congelamento ou por agentes químicos, como as soluções mercuriais, ácido acético glacial, ácido peracético, glutaraldeído e glicerina (RAISER et al., 2001; RABELO et al., 2004; LEAL et al, 2009).

A glicerina a $98 \%$ foi amplamente utilizada para conservar diferentes tecidos nas últimas quatro décadas, como dura-máter (PIGOSSI et al., 1967), peritônio de bovino, pericárdio de equino (RANZANI et al., 1990), peritônio de cão (DALECK et al., 1992), diafragma de cão (MAZZANTI et al., 2000), centro tendíneo diafragmático bovino (RABELO et al., 2004), osso de cão (AMENDOLA et al., 2008; VILELA et al., 2010), entre outros.

'Curso de Medicina Veterinária, Universidade Federal de Goiás (UFG), Campus Jataí (CAJ), 75804-020, Jataí, GO, Brasil. E-mail: aloisiosv@hotmail.com*Autor para correspondência.

"Departamento de Clínica e Cirurgia Veterinária, Universidade Estadual de São Paulo "Julio de Mesquita Filho" (UNESP), Campus de Jaboticabal, Jaboticabal, SP, Brasil.

'I'Laboratório de Bioquímica e Biomateriais, Instituto de Química de São Carlos, Universidade de São Paulo (USP), Campus de São Carlos, São Carlos, SP, Brasil.

${ }^{\mathrm{IV}}$ Curso de Zootecnia, Universidade Federal do Mato Grosso (UFMT), Campus de Cuiabá, Cuiabá, MT, Brasil. Recebido 03.12.11 $\quad$ Aprovado 06.03.13 $\quad$ Devolvido pelo autor 20.06.13 CR-6432 
Porém, modificações químicas em alguns tecidos animais constituem-se em alternativas de elevado potencial para alterar a antigenicidade e as propriedades do colágeno nele contidos, sejam elas mecânicas, estruturais ou físico-químicas. Matrizes colagênicas com superfícies carregadas ionicamente podem ser produzidas por reações químicas como as de esterificação e succinilação (JAYAKRISHNAM \& JAMELA, 1996).

GOISSIS et al. (1999) utilizaram solução alcalina em tecidos animais, promovendo hidrólise dos grupos carboxiamidas e aumentando até 106 cargas negativas por unidade de tropocolágeno. Essas alterações na estrutura do colágeno reduziram a antigenicidade tecidual e estimularam o crescimento celular (BET et al., 2001). A caracterização físico-química por espectroscopia na região do infravermelho demonstrou que a estrutura em hélice tripla do tropocolágeno foi preservada durante a hidrólise, ou seja, a unidade molecular do colágeno não foi alterada durante o processamento (GOISSIS et al., 1999).

A biocompatibilidade in vivo de materiais colagênicos tratados em solução alcalina foi pouco investigada. ROSA et al. (2003) obtiveram gel de colágeno aniônico a partir de pericárdio bovino e implantaram na calvária de ratos. Foi observado que o processo infamatório, em relação ao grupo controle, foi mais ameno. PARREIRA (2004) utilizou o processo de hidrólise alcalina em pericárdio bovino em amostras tratadas por 24 e 48 horas e as implantou no subcutâneo de ratos, observando o comportamento de integração tissular até 180 dias. Essas matrizes tiveram significativa diferença, em relação ao grupo controle, na redução da resposta inflamatória crônica, incluindo a fibrose.

O presente trabalho objetivou avaliar comparativamente a biocompatibilidade de biomembranas de colágeno, obtidas de centros tendíneos diafragmáticos, tratada em solução alcalina ou conservada com glicerina a $98 \%$ na parede abdominal de equinos.

\section{MATERIAL E MÉTODOS}

Etapa 1 - Obtenção das amostras

Os centros tendinosos diafragmáticos foram obtidos de equinos que morreram por causa conhecida, com exclusão das infectocontagiosas, e de animais submetidos à eutanásia no Hospital Veterinário Laudo Natel (HVLN) da Faculdade de Ciências Agrárias e Veterinárias (FCAV) da UNESP de Jaboticabal/SP.
Após a remoção, os centros tendinosos diafragmáticos foram lavados em solução de cloreto de sódio a $0,9 \%$ e permaneceram imersos por quatro horas na mesma solução, trocada a cada hora. Uma parte das amostras foi submetida a congelamento gradativo, sob temperatura de $15^{\circ} \mathrm{C}$ por 12 horas e $-15^{\circ} \mathrm{C}$ por 12 horas. Em seguida, foram submetidas à liofilização, processo que sublima a água presente no congelado, sob vácuo, até apresentarem massas constantes e esterilizadas em óxido de etileno, constituindo o grupo controle (Grupo GC). Outra parte das amostras foi conservada individualmente em frascos previamente esterilizados, contendo solução de glicerina a $98 \%$ (Glicerina Branca Rioquímica ${ }^{\circledR}$ ) durante 60 dias, conforme metodologia descrita por DALECK et al. (1992), constituindo o grupo glicerina $(\mathrm{GG})$. As amostras do grupo experimental (GE) foram preparadas no Laboratório de Bioquímica e Biomateriais do Instituto de Química da USP de São Carlos/SP. Tratou-se o material em solução alcalina, contendo dimetilsulfóxido e sais (cloretos e sulfatos) de sódio, potássio e cálcio. Após 72 horas de imersão, os sais residuais foram removidos por três lavagens sucessivas com ácido bórico a $3 \%$ e ácido etilenodiamino tetra-acético (EDTA) a $3 \%$. Posteriormente, as membranas foram congeladas gradativamente, conforme realizada com as amostras do GC, liofilizadas e esterilizadas em óxido de etileno (GOISSIS et al., 1999). A determinação do tempo de imersão em 72 horas foi determinada previamente (VULCANI et al., 2008).

Etapa 2 - Implantação e retirada das amostras

Para a implantação das amostras, foram utilizados seis equinos, três machos e três fêmeas, sem raça definida, adultos e hígidos. Os animais foram avaliados clinicamente, everminados com ivermectina a $1 \%$ (Ivomec - Merial $^{\circledR}$ ) e submetidos a período de adaptação alimentar e de manejo de dez dias.

Os equinos permaneceram em piquetes de capim tifton durante todo o período de experimentação, salvo durante o jejum alimentar e hídrico pré-cirúrgicos e a recuperação pós-operatória, durante os quais permaneceram em baias do HVLN da FCAV/UNESP. Os animais foram alimentados diariamente com feno, ração para equinos e água à vontade.

Para o procedimento, realizou-se a sedação dos animais com maleato de acepromazina $(0,10 \mathrm{mg}$ $\left.\mathrm{kg}^{-1}, \mathrm{IV}\right)$, indução da anestesia com éter gliceril guaicol (50 $\left.\mathrm{mg} \mathrm{kg}^{-1}, \mathrm{IV}\right)$, associado a tiopental sódico $\left(10^{3} \mathrm{mg}\right.$ $\left.200 \mathrm{~kg}^{-1}, \mathrm{IV}\right)$ e a manutenção desta por via inalatória com halotano, vaporizado em oxigênio a $100 \%$ em circuito semifechado (TRANQUILLI et al., 2007). 
Em cada animal, foram feitos três blocos cirúrgicos, constituídos por amostras dos três grupos, em posição alternada, de forma a minimizar o erro experimental, totalizando nove amostras por animal. Foi preconizado manter uma distância mínima de dez centímetros entre os blocos cirúrgicos e, em cada bloco, uma distância mínima de cinco centímetros entre as amostras implantadas. Antes da implantação, as amostras do GG foram lavadas e hidratadas com solução de cloreto de sódio a 0,9\% (DALECK et al., 1992).

Após tricotomia e antissepsia, foram feitas três incisões cutâneas paramedianas, sendo duas do lado direito e uma do lado esquerdo. Na região de cada incisão, divulsionou-se o subcutâneo, afastaramse as fibras do músculo reto abdominal, expondo seu folheto interno e retiraram-se três fragmentos $(2 \times 3 \mathrm{~cm})$ desta, para a fixação de uma amostra $(2 \times 3 \mathrm{~cm})$ da biomembrana de cada grupo (GE, GG ou GC), com sutura padrão contínuo simples com fio poliglactina 910 no 0 . O peritônio permaneceu íntegro e em contato com as amostras implantadas. $\mathrm{O}$ folheto externo foi suturado em padrão contínuo simples, com fio monofilamentar de poliamida ํㅡㄴ 2-0, o espaço morto subcutâneo foi reduzido com sutura em padrão Zigue Zague, com fio categute cromado ํㅡ 0 e a pele suturada em padrão colchoeiro horizontal contínuo, com fio monofilamentar de poliamida no 2-0. No período pós-cirúrgico imediato, os animais receberam dipirona $^{\mathrm{a}}\left(22 \mathrm{mg} \mathrm{kg}^{-1}, \mathrm{IV}\right)$ durante dois dias e penicilina procaína (22.000UI kg-1) (Agrovet - Novartis ${ }^{\circledR}$ ) por via intramuscular. $\mathrm{O}$ analgésico e o antibiótico foram administrados por mais dois dias consecutivos.

Em virtude da possível contaminação da ferida cirúrgica durante a permanência nos piquetes, realizou-se limpeza diária desta com líquido de Dakin, aplicação de tintura de iodo a $2 \%$ como repelente ao redor da ferida, durante oito dias consecutivos, quando foram removidas as suturas de pele.

Após as intervenções cirúrgicas, os animais foram avaliados clinicamente a fim de se verificar o seu estado de saúde e prevenir complicações, considerando-se os seguintes parâmetros: frequências cardíaca e respiratória, tempo de preenchimento capilar, temperatura retal, avaliação de mucosas e condições de cicatrização da ferida cirúrgica.

O primeiro bloco foi retirado sete dias após a implantação, o segundo 63 e o terceiro após 126 dias, seguindo-se os mesmos protocolos anestésico e cirúrgico descritos para a implantação das amostras. Ao término da retirada de todos os implantes, os animais foram acompanhados até a cicatrização total das feridas cirúrgicas e, em seguida, doados à FCAV, local onde ficaram mantidos em pastos e piquetes e inseridos ao plantel local.
Etapa 3 - Análise microscópica

Os fragmentos retirados cirurgicamente foram fixados por $24 \mathrm{~h}$ em formalina neutra e tamponada a $10 \%$, e processados rotineiramente para inclusão em parafina. As amostras foram coradas por hematoxilina-eosina (HE), Tricrômio de Gomori e Von-Kossa. Para a análise microscópica, utilizouse microscópio binocular com equipamento para fotomicrografia, câmera de captação de imagem e analisador de imagens. De cada corte histológico, foram escolhidos 20 campos aleatórios (área estabelecida de $23089,96 \mu^{2} \mathrm{~m}^{-1}$ por campo), avaliados sempre pelo mesmo patologista, não conhecedor da identidade das amostras. Os seguintes parâmetros foram avaliados: presença de cápsula fibrosa; classificação e contagem de células (linfócitos, polimorfonucleares, macrófagos, células gigantes multinucleadas do tipo corpo estranho), fibroblastos; ocorrência de neovascularização; ocorrência de metaplasia óssea (presença de osteoide, osteoblastos, osteoclastos e/ou osso mineralizado).

O delineamento experimental utilizado foi inteiramente casualisado em esquema fatorial três por três, com os fatores GC, GG e GE e coletas das amostras aos sete, 63 e 126 dias pós-implantação. Analisou-se também a interação dos fatores estudados com o sexo dos animais.

Foi realizada análise de normalidade dos erros estudentizados (teste de Cramer-Von Mises) e de homogeneidade de variâncias (teste de BrownForsythe). Após verificação do atendimento dessas pressuposições, os dados foram submetidos à análise de variância, empregando-se o General Linear Model do programa $\mathrm{SAS}^{\circledR} \mathrm{e}$, em caso de diferença $(\mathrm{P} \leq 0,05)$, as médias foram comparadas pelo teste Tukey, considerando-se o nível de $5 \%$ de probabilidade (SAMPAIO, 1998).

\section{RESULTADOS}

Os parâmetros clínicos (frequências cardíaca e respiratória, tempo de preenchimento capilar, temperatura retal, avaliação de mucosas e condições de cicatrização da ferida cirúrgica) obtidos após os procedimentos cirúrgicos de implantação e retirada das amostras não mostram alterações dignas de nota.

Os valores médios das contagens das células envolvidas no processo inflamatório e cicatricial estão mostrados na tabela 1 . Na contagem de polimorfonucleares, houve diferença $(\mathrm{P} \leq 0,05)$ entre os tratamentos e entre os tratamentos e os períodos de coleta. Aos sete dias pós-implantação, 
houve maior infiltrado de polimorfonucleares para os grupos GC e GG, cujas médias não diferiram entre si, mas diferiram do GE. Observou-se, também, que o infiltrado em GE predominou na periferia do implante e, em GG, as células invadiram o interior do implante (Figura 1 A e B). Aos 63 e 126 dias pós-implantação, houve diferença entre os três tratamentos; o GC apresentou média maior, seguido dos GG e GE. Analisando-se os tratamentos nos diferentes períodos de coleta, observou-se que houve decréscimo das médias das contagens de polimorfonucleares para os três tratamentos.

$\mathrm{Na}$ contagem de linfócitos, houve diferença $(\mathrm{P} \leq 0,05)$ entre os tratamentos e para a interação entre os tratamentos e os períodos de coleta. Observou-se, aos sete dias pós-implantação, que não houve diferença entre os tratamentos. Aos 63 e 126 dias, os grupos GC e GG não diferiram entre si, mas diferiram do grupo GE, que apresentou média menor. Analisando-se a interação entre os tratamentos e períodos de coleta, verificou-se, para os grupos GC e GG, aumento das médias de linfócitos no sexagésimo terceiro dia pós-implantação e decréscimo das médias no dia 126 pós-coleta. Para o GE, houve queda das médias da contagem de linfócitos a partir do sétimo dia pós-implantação.

$\mathrm{Na}$ contagem de macrófagos, houve diferença $(\mathrm{P} \leq 0,05)$ entre os tratamentos e para a interação entre os tratamentos e os períodos de coleta. Aos sete, 63 e 126 dias pós-implantação houve diferença entre o grupo GE e os demais grupos. Porém, não houve diferença entre os grupos GG e GC. Observando-se a interação entre os tratamentos com os períodos de coleta, para a contagem de macrófagos, observou-se que os três grupos apresentaram aumento das médias aos 63 dias. Aos 126 dias pós-implantação, observa-se diminuição das médias dos grupos GC e GE.

$\mathrm{Na}$ contagem de fibroblastos, houve diferença $(\mathrm{P} \leq 0,05)$ entre os tratamentos e para a interação entre os tratamentos e os períodos de coleta. Aos sete e 63 dias pós-implantação, houve menor média do grupo GC em relação aos grupos GG e GE. Aos 126 dias, houve maior média do grupo GE. Na interação entre os tratamentos com os períodos de coleta, para a contagem de fibroblastos, observou-se que os três tratamentos tiveram aumento progressivo da média de fibroblastos, culminando aos 126 dias com diferença do grupo GE em relação aos grupos GC e GG, que não diferiram entre si (Figura 1C).

Em relação à angiogênese, notou-se que não ocorreu aos sete dias. Porém, após 63 e 126 dias pós-implante, verificaram-se neovasos nos três grupos, com médias diferentes $(\mathrm{P} \leq 0,05)$ em relação aos sete dias (Figura 1D).

Tabela 1 - Médias das contagens de polimorfonucleares, linfócitos, macrófagos e fibroblastos adjacentes às biomembranas de colágeno, tratadas em solução salina (GE), conservadas em glicerina $98 \%(\mathrm{GG})$ e não tratadas (GC), retiradas aos sete, 63 e 126 dias pósimplantação no músculo reto abdominal de equinos.

\begin{tabular}{|c|c|c|c|}
\hline Tipo celular & 7 & 63 & 126 \\
\hline ------ & ------------------ & ares-------------' & 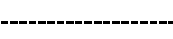 \\
\hline $\mathrm{GC}$ & $401,8 \pm 1,1^{\mathrm{Aa}}$ & $385,5 \pm 3,0^{\mathrm{Ab}}$ & $293,50 \pm 2,3^{\mathrm{Ac}}$ \\
\hline GG & $398,3 \pm 3,1^{\mathrm{Aa}}$ & $369,0 \pm 2,1^{\mathrm{Bb}}$ & $257,67 \pm 1,3^{\mathrm{Bc}}$ \\
\hline GE & $306,0 \pm 2,2^{\mathrm{Ba}}$ & $224,8 \pm 1,9^{\mathrm{Cb}}$ & $7,50 \pm 3,3^{\mathrm{Cc}}$ \\
\hline GC & $42,3 \pm 3,5^{\mathrm{Ab}}$ & $63,67 \pm 4,0^{\mathrm{Aa}}$ & $38,33 \pm 5,0^{\mathrm{Ab}}$ \\
\hline GG & $42,6 \pm 2,1^{\mathrm{Ab}}$ & $64,50 \pm 2,1^{\mathrm{Aa}}$ & $38,83 \pm 4,6^{\mathrm{Ab}}$ \\
\hline GE & $39,3 \pm 2,0^{\mathrm{Aa}}$ & $25,67 \pm 1,4^{\mathrm{Bb}}$ & $6,83 \pm 2,9^{\mathrm{Bc}}$ \\
\hline $\mathrm{GC}$ & $26,0 \pm 3,1^{\mathrm{Aa}}$ & $48,1 \pm 3,5^{\mathrm{Ab}}$ & $27,6 \pm 2,1^{\mathrm{Aa}}$ \\
\hline GG & $23,1 \pm 2,3^{\mathrm{Aa}}$ & $35,8 \pm 2,8^{\mathrm{Ab}}$ & $33,5 \pm 1,0^{\mathrm{Ab}}$ \\
\hline $\mathrm{GE}$ & $15,5 \pm 1,9^{\mathrm{Ba}}$ & $27,5 \pm 1,2^{\mathrm{Bb}}$ & $11,3 \pm 1,9^{\mathrm{Ba}}$ \\
\hline $\mathrm{GC}$ & $7,1 \pm 0,9^{\mathrm{Bc}}$ & $44,6 \pm 2,7^{\mathrm{Bb}}$ & $57,5 \pm 3,5^{\mathrm{Ba}}$ \\
\hline GG & $16,3 \pm 1,2^{\mathrm{Ab}}$ & $65,5 \pm 1,0^{\mathrm{Aa}}$ & $62,8 \pm 1,2^{\mathrm{Ba}}$ \\
\hline GE & $17,6 \pm 1,8^{\mathrm{Ac}}$ & $68,6 \pm 2,3^{\mathrm{Ab}}$ & $77,0 \pm 2,0^{\mathrm{Aa}}$ \\
\hline
\end{tabular}

Médias seguidas de letras iguais maiúsculas na coluna não diferem entre si pelo teste Tukey (P>0,05). Médias seguidas de letras iguais minúsculas na linha não diferem entre si pelo teste Tukey $(\mathrm{P}>0,05)$.

Ciência Rural, v.43, n.8, ago, 2013. 


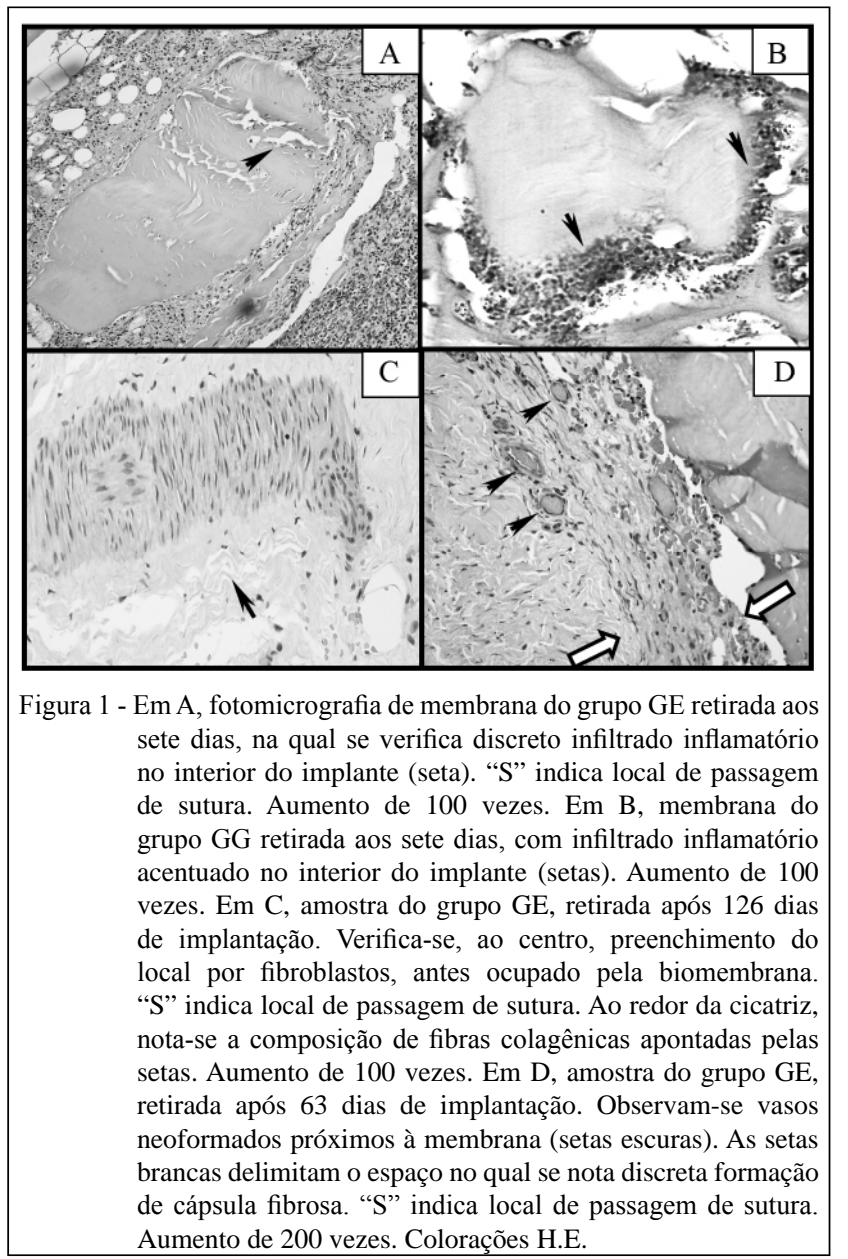

As células gigantes multinucleadas do tipo corpo estranho foram observadas apenas no grupo GC e não foi observada metaplasia de células musculares que estiveram em contato com os implantes em nenhum dos grupos estudados nos três períodos.

Com relação à interação dos fatores estudados com o sexo dos animais, não foram verificadas diferenças entre os grupos $(\mathrm{P}>0,05)$.

\section{DISCUSSÃO}

Em relação ao processo inflamatório, verificou-se que ocorreu diminuição gradual de polimorfonucleares dos sete ao 63ํ dia pósimplantação nos três grupos estudados, seguindo um padrão de inflamação aguda (SIQUEIRA \& DANTAS, 2000). No entanto, no 63ํ e 126음 dias pós-implantação, observou-se que os grupos GC e GG expressaram maior quantidade absoluta de polimorfonucleares em relação ao grupo GE. Esse comportamento de ambos os grupos de comparação é característico de processo inflamatório crônico ativo, no qual observa-se que há sobreposição dos elementos característicos de um processo inflamatório agudo e crônico (COTRAN et al., 2000).

A reação de agranulócitos, característica de inflamação crônica (COTRAN et al., 2000), também foi mais intensa nos grupos GC e GG. Nota-se que a quantidade de linfócitos aumentou consideravelmente em ambos os grupos aos sete e 63 dias após a implantação das amostras. Comportamento oposto pode ser verificado no grupo GE, no qual se observou decréscimo da quantidade de linfócitos a partir dos sete dias pós-implantação.

Esse padrão histológico, verificado no grupo GE, foi observado por ROSA et al. (2003) em implantes de matrizes aniônicas de colágeno na calvária de ratos e por PARREIRA(2004) em implantes de matrizes aniônicas de colágeno no subcutâneo de ratos, demonstrando menor antigenicidade das amostras tratadas em solução alcalina.

O aumento de macrófagos no sétimo e no 63ํ dias pós-implantação, com maior intensidade para os grupos GC e GG, sugere relação com o tempo 
de degradação das amostras. Inicialmente, há maior quantidade de massa, estimulando a proliferação de macrófagos para biodegradação do material. ROSA et al. (2003) observaram o mesmo padrão em implantes de colágeno sem tratamento, correlacionando a reação inflamatória com o tempo de permanência do implante no hospedeiro.

No entanto, para o grupo GE, cuja degradação mostrou-se mais rápida, houve declínio acentuado de macrófagos e aumento da migração de fibroblastos, em relação aos grupos GC e GG, corroborando os achados de ROSA et al. (2003) e PARREIRA (2004). A formação e manutenção de cápsula fibrosa mais regular nas amostras do grupo GE em relação aos GC e GG sugeriram que o processo inflamatório causado por biomateriais sofreria resolução mais rápida no grupo GE, fato que foi reforçado pelas quantidades de macrófagos e fibroblastos observados nos três grupos (ANSTEAD, 1998). No entanto, não houve persistência na formação completa de cápsula fibrosa no grupo GE, o que pode estar relacionado à degradação das amostras, cuja diminuição gradual de massa favorece a cicatrização ou regeneração, não havendo a necessidade de encapsulamento, que é um comportamento típico da bioatividade de materiais degradáveis (HENCH et al., 2006).

A avaliação histológica experimental de implantes na parede abdominal tem sido feita com grande frequência, porém, em espécies como ratos, coelhos e em menor instância em cães (VULCANI et al., 2009). São raros os trabalhos com grandes animais, cujo enfoque está na aplicação clínico-cirúrgica de biomateriais para a correção de hérnias e eventrações (STELMANN et al., 2010), não permitindo avaliações microscópicas na interface da implantação, mas somente avaliações macroscópicas da resolução da ferida e dos efeitos sistêmicos nos animais.

\section{CONCLUSÃO}

Nas condições de execução deste trabalho, concluiu-se que a biomembrana tratada em solução alcalina proporciona, na interface de implantação da parede abdominal de equinos, processo inflamatório menos intenso e menos persistente em relação ao material não tratado e ao conservado em glicerina $98 \%$. Portanto, as biomembranas colagênicas tratadas em solução alcalina são mais biocompatíveis do que biomembranas conservadas em glicerina $98 \%$.

\section{FONTES DE AQUISIÇÃO}

a - D 500 - Hoecsht do Brasil Química e Farmacêutica S.A.
COMISSÃO DE ÉTICA E BIOSSEGURANÇA

Aprovado pela comissão de ética e bem-estar animal, n⿳0 005024-05

\section{REFERÊNCIAS}

AMENDOLA, G.F. Aspectos biomecânicos compressivos de diáfises femorais caninas conservadas em glicerina a $98 \%$ ou em mel. Ciência Rural, Santa Maria, v.38, n.5, p.13411345, 2008. Disponível em: <http://www.scielo.br/scielo. php?script=sci_arttext\&pid=S0103-84782008000500022\&lng=en \&nrm=iso>. Acesso em: 27 fev. 2013. doi.org/10.1590/S010384782008000500022

ANSTEAD, G.M. Steroids, retinoids, and wound healing. Advanced Wound Care, v.11, n.6, p.277-285, 1998. Disponível em: <http://www.ncbi.nlm.nih.gov/pubmed/10326344>. Acesso em: 01 mar. 2013.

BELLÓN, J.M. Propuesta de una nueva clasificación de prótesis destinadas a la reparación de defectos herniarios em la pared abdominal. Cirúrgica Española, v.78, n.3, p.148-151, 2005. Disponível em: <http://www.elsevier.es/es/revistas/cirugiaespa $\% \mathrm{C} 3 \%$ B1ola-36/propuesta-una-nueva-clasificacion-protesisdestinadas-reparacion-13078297-articulo-especial-2005 ?bd=1>. Acesso em: 01 mar. 2013.

BET, M.R. et al. Characterization of polyanionic collagen prepared by selective hydrolysis of asparagine and glutamine carboxyamide side chains. Biomacromolecules, v.2, p.10741079, 2001. Disponível em: <http://www.ncbi.nlm.nih.gov/ pubmed/11777376>. Acesso em: 01 mar. 2013.

COTRAN, R.S et al. Patologia estrutural e funcional. Rio de Janeiro:Guanabara Koogan, 2000. 1348p.

DALECK, C.R. et al. Reparação de hérnia perineal em cães com peritônio de bovino conservado em glicerina. Ciência Rural, v.22, n.2, p.179-183, 1992.

GOISSIS, G. et al. Surface tension controll of collagen biomaterials by the selective hydrolysis of internal carboxyamides of the protein matrix. Revista Brasileira de Engenharia Biomédica, v.15, n.1-2, p.55-61, 1999. Disponível em: <http:// rbeb.ceb.unicamp.br/artigos/rev15/n1_2/art-h_15_1_2.pdf >. Acesso em: 01 mar. 2013.

HENCH, L.L. et al. Biocompatibilidade, bioatividade e engenharia de tecidos. In: ORÉFICE, R.L. et al. Biomateriais: fundamentos e aplicações. Rio de Janeiro: Cultura Médica, 2006. Cap.16, p.479506.

JAYAKRISHNAM, A.; JAMELA, S.R. Glutaraldehyde as a fixative in bioprosthese and drug delivery matrices. Biomaterials, v.17, n. 5, p.471-484, 1996.

OLIVEIRA, L.L. et. al. Métodos de preservação de membranas biológicas para uso cirúrgico. Jornal Brasileiro de Ciência Animal, v.2, n.3, p.175-188, 2009. Disponível em: <http:// www.jbca.com.br/v2n3/novos_artigos/formatado_membranas_ biologicas.pdf>. Acesso em: 01 mar. 2013.

MAZZANTI, A. et al. Reparação da traquéia de cão com segmento muscular homólogo de diafragma conservado em 
glicerina a 98\%. Ciência Rural, v.30, n.6, p.1011-1016, 2000. Disponível em: <http://www.scielo.br/scielo.php?pid=s010384782000000600015\&script=sci_arttext $>$. Acesso em: 01 mar. 2013.

PARREIRA, D.R. Matrizes tridimensionais de colágeno aniônico: elastina como suporte para reconstrução de tecidos moles: um estudo de integração matriz:tecido. 2004. 56f. Dissertação (Mestrado em Bioengenharia) - Curso de Pós-graduação em Bioengenharia - Interunidades, Escola de Engenharia de São Carlos, Faculdade de Medicina de Ribeirão Preto, Instituto de Química de São Carlos, SP.

PIGOSSI, N. A glicerina na conservação de dura-máter - estudo experimental. 1967. 36f. Tese (Livre docência) - Faculdade de Medicina de São Paulo, Universidade de São Paulo, SP.

RABELO, R.E. et al. Características físicas e microbiológicas do centro tendíneo diafragmático bovino conservado em glicerina a 98\% e no glutaraldeído a 4\%. Ciência Animal Brasileira, v.5, n.4, p.229-238, 2004. Disponível em: <http://www.revistas.ufg.br/ index.php/vet/article/view/335>. Acesso em: 01 mar. 2013.

RAISER, A.G. et al. Homoimplante ortotópico de tendão calcâneo em cães. Conservação assepsia e implantação. Ciência Rural, v.31, n.1, p.89-94, 2001. Disponível em: <http://www.scielo.br/ pdf/cr/v31n1/a14v31n1.pdf >. Acesso em: 01 mar. 2013.

RANZANI, J.J.T. et al. Implante de pericárdio de equino preservado em glicerina em solução de continuidade do diafragma de cão. Brazilian of Journal Veterinary Research and Animal Science, v.27, n.1, p.65-73, 1990. Disponível em: <http://www. revistas.usp.br/bjvras/article/viewFile/51839/55892>. Acesso em: 01 mar. 2013.
ROSA, F.P. et al. Tissue response polyanionic collagen:elastin matrices implanted in rat calvaria. Biomaterials, v.24, n.2, p.207-212, 2003. Disponível em: <http://www.ncbi.nlm.nih.gov/ pubmed/12419620>. Acesso em: 01 mar. 2013.

SAMPAIO, I.B.M. Estatística aplicada à experimentação animal. Belo Horizonte: Fundação de Ensino e Pesquisa em Medicina Veterinária e Zootecnia, 1998. 221p.

SIQUEIRA, J.F; DANTAS, C.J.S. Mecanismos celulares e moleculares da inflamação. Rio de Janeiro: MEDSI, 2000. 238p.

STELMANN, U.J.P. et al. Utilização de pericárdio bovino como reforço da rafia do peritônio no tratamento cirúrgico de eventração em equino: relato de caso. Revista Cientifica Eletrônica de Medicina Veterinária, n.14, p.112-116, 2010. Disponível em: <http://www.revista.inf.br/veterinaria14/relatos/RCEMVAnoVIII-Edic14-RC12.pdf>. Acesso em: 01 mar. 2013.

TRANQUILLI, W.J. et al. Lumb and Jones` veterinary anesthesia and analgesia. Iowa: Blackwell, 2007. 1096p.

VILELA, L.M. et al. Avaliação das fibras colágenas de meniscos frescos e preservados em glicerina: estudo experimental em coelhos (Oryctolagus cuniculus). Pesquisa Veterinária Brasileira, v.30, n.4, p.321-327, 2010.

VULCANI, V.A.S. et al. Biomateriais para reparação cirúrgica da parede abdominal em animais domésticos - Revisão. Arquivo de Ciências Veterinárias e Zoologia, v.12, n.2, p.141-147, 2009

VULCANI, V.A.S. et al. Obtenção, caracterização e aplicação cirúrgica de matrizes de colágeno na parede abdominal de equinos. Ciência Animal Brasileira, v.9, n.3, p.778-785, 2008. 